\title{
Pro-apoptotic effects of pycnogenol on HT1080 human fibrosarcoma cells
}

\author{
KAMRAN HARATI $^{1}$, PAWEL SLODNIK ${ }^{1}$, ANSGAR MICHAEL CHROMIK ${ }^{2}$, BJÖRN BEHR ${ }^{1}$, \\ OLE GOERTZ $^{1}$, TOBIAS HIRSCH ${ }^{1}$, NICOLAI KAPALSCHINSKI ${ }^{1}$, LUDGER KLEIN-HITPASS ${ }^{3}$, \\ JONAS KOLBENSCHLAG ${ }^{1}$, WALDEMAR UHL ${ }^{2}$, MARCUS LEHNHARDT ${ }^{1}$ and ADRIEN DAIGELER ${ }^{1}$ \\ ${ }^{1}$ Department of Plastic Surgery, Burn Center, Hand Center, Sarcoma Reference Center, BG-University \\ Hospital Bergmannsheil, Ruhr-University Bochum, D-44789 Bochum; ${ }^{2}$ Department of General and \\ Visceral Surgery, St. Josef Hospital, Ruhr-University Bochum, D-44791 Bochum; ${ }^{3}$ Institute of Cell \\ Biology (Cancer Research), University of Duisburg-Essen, D-45122 Essen, Germany
}

Received November 15, 2014; Accepted December 23, 2014

DOI: 10.3892/ijo.2015.2854

\begin{abstract}
Complete surgical resection with clear margins remains the mainstay of therapy for localised fibrosarcomas. Nevertheless, metastatic fibrosarcomas still represent a therapeutic dilemma. Commonly used chemotherapeutic agents like doxorubicin have proven to be effective in $<30 \%$ of all cases of disseminated fibrosarcoma. Especially elderly patients with cardiac subdisease are not suitable for systemic chemotherapy with doxorubicin. Therefore we tested the apoptotic effects of the well-tolerated pine bark extract pycnogenol and its constituents on human fibrosarcoma cells (HT1080). Ten healthy subjects (six females, four males, mean age $24.8 \pm 6$ years) received a single dose of $300 \mathrm{mg}$ pycnogenol orally. Blood plasma samples were obtained before and $6 \mathrm{~h}$ after intake of pycnogenol. HT1080 cells were treated with these plasma samples. Additionally, HT1080 were incubated separately with catechin, epicatechin and taxifolin that are known as the main constituents of pycnogenol. Vital, apoptotic and necrotic cells were quantified using flow cytometric analysis. Gene expression was analyzed by RNA microarray. The results showed that single application of taxifolin, catechin and epicatechin reduced cell viability of HT1080 cells only moderately. A single dose of $300 \mathrm{mg}$ pycnogenol given to 10 healthy adults produced plasma samples that led to significant apoptotic cell death ex vivo whereas pycnogenol-negative serum displayed no apoptotic activity. Microarray analysis revealed remarkable expression changes induced by pycno-
\end{abstract}

Correspondence to: Dr Kamran Harati, Department of Plastic Surgery, Burn Center, Hand Center, Sarcoma Reference Center, BG-University Hospital Bergmannsheil, Ruhr-University Bochum, Buerkle-de-la-Camp-Platz 1, D-44789 Bochum, Germany

E-mail: kamran.harati@t-online.de

Key words: soft tissue sarcoma, fibrosarcoma, cancer, pycnogenol, catechin, epicatechin, taxifolin, apoptosis, necrosis, gene expression, fluorescence-activated cell sorting, LAMC1, RHOA, FN1, CTNNA1, JAK1, ITGB1 genol in a variety of genes, which are involved in different apoptotic pathways of cancer cells [Janus kinase 1 (JAKl), DUSP1, RHOA, laminin $\gamma 1$ (LAMC1), fibronectin 1 ( $F N 1$ ), catenin $\alpha 1$ (CTNNA1), ITGB1]. In conclusion, metabolised pycnogenol induces apoptosis in human fibrosarcoma cells. Pycnogenol exhibits its pro-apoptotic activity as a mixture and is more effective than its main constituents catechin, epicatechin and taxifolin indicating that the metabolised components interact synergistically. These results provide experimental support for in vivo trials assessing the effect of the pine bark extract pycnogenol.

\section{Introduction}

Soft tissue sarcomas are a heterogeneous group of solid malignant tumours which represent $\sim 1 \%$ of all new cancer cases in Europe and the United States (1). Fibrosarcomas are rare soft tissue sarcomas originating from the intra- and intermuscular fibrous tissues, fascia and tendons and account for $~ 3 \%$ of all soft tissue sarcomas. Therapy for fibrosarcomas should be individualised and multimodal. The therapy of choice involves surgical resection with a wide margin of healthy tissue, usually followed by radiation treatment in order to decrease local recurrence $(2,3)$. Unfortunately, $\sim 50 \%$ of all patients develop distant metastases and are ineligible for surgical treatment $(4,5)$. In cases of advanced metastatic disease the median survival time with and without chemotherapy treatment is $<12$ months $(6,7)$. Few agents such as doxorubicin, ifosfamide and dacarbazine have proven to be effective in the therapy of soft tissue sarcomas (2). However, the results of these treatments are poor and often exhibit no significant improvements in overall survival (8). Doxorubicin, which has been the most frequently used chemotherapeutic agent in the treatment of soft tissue sarcomas, demonstrates response rates of $20-30 \%$ in disseminated disease $(9,10)$. The combination of doxorubicin with ifosfamide is more effective, exhibiting higher response rates than doxorubicin alone, but is associated with severe short- and long-term toxicities, including cardiomyopathy and bone marrow suppression (11-13). The recently published EORTC 62012 trial which 
involved 455 patients with locally advanced, unresectable or metastatic high-grade soft tissue sarcomas concluded that an intensified therapy with doxorubicin and ifosfamide is not suitable for palliation of advanced soft tissue sarcomas because of the severe side-effects and should only be used when the specific goal is tumour shrinkage (13). Further, the utility of the first-line cytostatic doxorubicin is limited by dose-related and cumulative myocardial toxicity, especially in elderly patients with pre-existing cardiac disease (14). However, age is an important determinant of sarcoma occurrence and the incidence of soft tissue sarcomas increases dramatically at ages $>50$ years and above which are naturally associated with higher prevalence of cardiac diseases (15). To date, there are no effective and well-tolerated cytostatics for the palliative treatment of patients who are not suitable for aggressive anthracycline-based chemotherapy. Hence, there is still a need for alternative and well-tolerated compounds that exhibit antineoplastic effects in sarcoma cells.

Within the scope of this trial, we investigated the effects of the natural pine bark extract pycnogenol on human fibrosarcoma cells. Pycnogenol is a brand name for an extract obtained from the bark of the Pinus pinaster pine tree by a standardised process. It is manufactured by Horphag Research, Ltd. (Geneva, Switzerland) and is available as a nutritional supplement in the United States and in Europe. Pycnogenol is primarily composed of a mixture of flavonoids, mainly procyanidins and phenolic acids. It is standardised to contain $\sim 65-75 \%$ procyanidins that consist of taxifolin, catechin and epicatechin subunits of varying chain length (16). Other constituents are polyphenolic monomers, cinnamic acids and their glycosides (17).

Since pycnogenol is a naturally occurring compound that is very well-tolerated with a high oral bioavailability, it has been highly studied for the treatment of many diseases including cancer $(17,18)$. Several in vitro studies demonstrated the anticancer activity of pycnogenol in a wide range of malignant cell lines including leukemia, ovarian and breast cancer cells (19-21). Moreover, pycnogenol has been reported to alleviate adverse effects of oncologic treatment in a clinical trial with 64 chemotherapy patients (22). Patients receiving pycnogenol during chemotherapy treatment had a significant decreased incidence of side-effects such as nausea, vomiting, diarrhoea and weight loss when compared with patients from the control group.

Inspired by these findings, we examined in the following study the apoptosis-inducing activity of pycnogenol and its constituents on human fibrosarcoma cells.

\section{Materials and methods}

Volunteers. Ten healthy female (six) and male (four) subjects aged $18-31$ years (mean age $24.8 \pm 6$ years) participated in this study. All participants gave written informed consent. The study was reviewed and approved by the Ethics Committee of the BG-University Hospital Bergmannsheil, Ruhr-University Bochum, Germany with the permit no. 3162-08.

Protocol of pycnogenol intake. After a 24-h diet free of flavonoids (no vegetables, fruits, marmalades, tea, coffee, cocoa, wine and beer) blood samples were taken from the
10 volunteers. Subsequently, the volunteers received a single dose of $300 \mathrm{mg}$ pycnogenol (Pycnogenol ${ }^{\circledR}$; Horphag Research, Ltd., London, UK) per os with $200 \mathrm{ml}$ water. Flavonoid-free diet was continued by the volunteers for another $6 \mathrm{~h}$. Blood samples were taken again $6 \mathrm{~h}$ after pycnogenol intake. All blood samples were centrifuged and plasma was aliquoted, frozen and stored at $-80^{\circ} \mathrm{C}$ until further analysis.

Cell line. Human fibrosarcoma cells, HT1080, were purchased from American Type Culture Collection (ATCC) (cell line CCI 121; Wesel, Germany) and maintained in modified Eagle's medium (MEM) and non-essential amino acids (NEAA) + 10\% fetal bovine serum (FBS) supplemented with $1 \%$ penicillin $(100 \mathrm{U} / \mathrm{ml})$ and streptomycin $(100 \mu \mathrm{g} / \mathrm{ml}), 1 \%$ sodium pyruvate and $1 \% \mathrm{~L}$-glutamine. The cells were cultured in a humidified atmosphere at $37^{\circ} \mathrm{C}$ with $5 \% \mathrm{CO}_{2}$ in $25 \mathrm{~cm}^{2}$ flasks.

Reagents. Pycnogenol was obtained from Horphag Research, Ltd. (Geneva, Switzerland). Catechin, epicatechin and taxifolin were obtained from Sigma-Aldrich (St. Louis, MO, USA) and dissolved in distilled water obtaining a concentration of $11.25 \mathrm{ng} / \mathrm{ml}$ (catechin), $6.25 \mathrm{ng} / \mathrm{ml}$ (epicatechin) and $6.25 \mathrm{ng} / \mathrm{ml}$ (taxifolin). The concentrations of catechin and taxifolin are achievable mean concentrations in human plasma several hours after single oral intake of catechin and taxifolin, respectively $(16,23)$. There were no data available regarding pharmacokinetics and achievable concentrations of epicatechin in human plasma after oral intake.

Cell treatment. For every drug experiment, $80 \mu \mathrm{l}$ of $3 \times 10^{6}$ cells $/ \mathrm{ml}$ were placed in 6 -well plates containing the medium. After $24 \mathrm{~h}$, the medium was replaced and the drugs (catechin, epicatechin, taxifolin) or diluted plasma samples were added to each well at the above-mentioned concentrations. Different time points were chosen to identify the possible time dependency of the effects. All experiments were repeated for each of three consecutive passages.

Flow cytometric analysis. At the indicated incubation time, the floating cells were collected together with the supernatant and adherent cells, which were harvested by trypsinisation. The cells were pelleted by centrifugation, resuspended in $195 \mu$ l binding buffer (Bender MedSystems, Vienna, Austria) and incubated with $5 \mu \mathrm{l}$ Annexin V (BD Biosciences, Heidelberg, Germany) and $10 \mu \mathrm{l}$ propidium iodide (PI) (Bender MedSystems) following the manufacturer's instructions. The cells were analysed immediately using a FACSCalibur flow cytometer (BD Biosciences). For each measurement, 20,000 cells were counted. Dot plots and histograms were analysed using CellQuest Pro Software (BD Biosciences). Annexin $\mathrm{V}$ binds phosphatidylserine on the outer membranes of cells, which then becomes exposed on the surface of apoptotic cells. Thus, the Annexin V-positive cells are considered apoptotic. PI is an intercalating agent that cannot permeate through the cell membranes of viable or early apoptotic cells. Therefore, PI stains only the DNA of necrotic or very late apoptotic cells. In this study, Annexin V- and PI-positive cells were termed necrotic. Annexin V- and PI-negative cells were counted as viable. 
Cell morphology. The morphology of the adherent and suspended cells was examined and documented using a phase contrast Zeiss Axiovert 25 microscope (Carl Zeiss, Jena, Germany).

Statistical analysis. The results of FACS analysis were used to determine the percentages of viable, apoptotic and necrotic cells, which are expressed as the means \pm SD from at least three independent experiments and consecutive passages. In this study, comparisons between the experimental groups were performed using one-way measures of variance (one-way ANOVAs) over all time points (Tukey's test). Results were considered statistically significant for $\mathrm{p} \leq 0.05$.

Oligonucleotide microarray analysis. To identify the changes in gene expression levels caused by the treatment with the tested substances or plasma samples, total RNA was purified from the cells after incubation with the appropriate agent for $6 \mathrm{~h}$ using a RNeasy kit from Qiagen (Hilden, Germany) as specified by the manufacturer. RNA integrity was assessed using an Agilent 2100 Bioanalyzer (Agilent Technologies, Inc., Santa Clara, CA, USA). For microarray analyses, we applied the methods previously described by Daigeler et al (24). We used the Affymetrix GeneChip platform, employing a standard protocol for sample preparation and microarray hybridisation. A one-way ANOVA model followed by Tukey's honestly significant difference (HSD) test was used to verify the hypothesis that there were no differences in expression between the drug-treated and the control group. The multiplicity correction was performed using Benjamini-Hochberg procedure to control the false discovery rate (FDR) at $0.05 \%$. In a pair-wise comparison of the differentially expressed genes between the control and the treated cells identified by the ANOVA analyses, a subset of genes was identified that displayed a conjoint regulation in the treated cells. Genes were placed in this latter group if they exhibited a mean $\geq 2$-fold increase or decrease compared to the control cells. This subset of genes was subjected to the GeneTrail (25) software to identify any over-representation of genes associated with the regulatory pathways that are represented in the Kyoto Encyclopaedia of Genes and Genomes (KEGG) and TRANSPATH databases. Microarray data are deposited in the GEO public database (accession no. GSE59704). These methods fulfilled the MIAME criteria (http://www.mged. org/miame).

\section{Results}

Single applications of catechin, epicatechin and taxifolin are not effective in reducing cell viability of HT1080 fibrosarcoma cells. The viability of the HT1080 cells was moderately but significantly reduced by single treatment with taxifolin (Fig. 1). A total of $82.5 \pm 1.7 \%$ (mean \pm SD) of the cells were detected as viable after $24 \mathrm{~h}$ treatment with taxifolin (vs. $94.9 \pm 0.6 \%$ in the control group, $\mathrm{p}=0.001$ ). Single treatment with catechin led also to significant reduction of viable cells after $24 \mathrm{~h}$ of incubation, but only a slight decrease in cell viability was observed; the percentage of viable cells was reduced to $87.2 \pm 1.0 \%$ ( $\mathrm{p}<0.001)$. Exposure to epicatechin alone decreased cell viability likewise to $87.1 \pm 0.9 \%(\mathrm{p}<0.001)$.
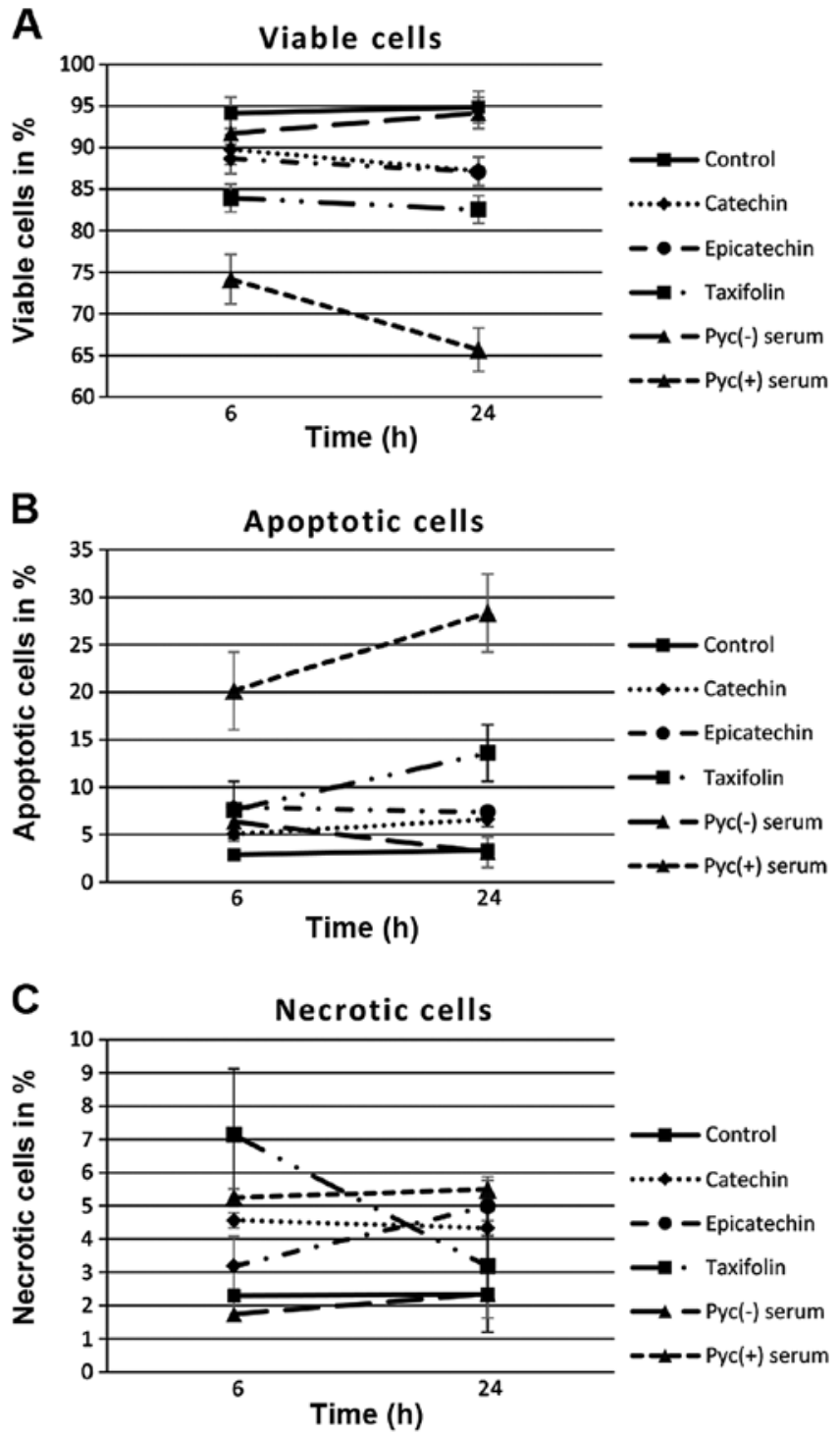

Figure 1. Effects of pycnogenol and its metabolites on viability, apoptosis and necrosis. HT1080 cells were incubated for $24 \mathrm{~h}$ with catechin, epicatechin, taxifolin, plasma samples after and before pycnogenol intake. The percentages of (A) viable, (B) apoptotic and (C) necrotic cells were determined using fluorescence activated cell sorting (FACS) analysis for Annexin V-FITC and propidium iodide $(\mathrm{PI})$. The values indicate the means \pm SD of three independent experiments and consecutive passages. Pyc(+), plasma sample after pycnogenol intake; Pyc(-), plasma sample before pycnogenol intake.

Plasma samples obtained after pycnogenol intake induced significantly apoptotic cell death. Application of plasma samples before pycnogenol intake had no significant effect on cell viability over all time points (Fig. 1). After 24-h treatment with pycnogenol-negative human plasma $94.2 \pm 1.0 \%$ of the cells were detected as viable. In contrast, the viability of untreated control cells was $94.9 \pm 1.4 \%$. Strikingly, treatment of HT1080 cells with plasma samples after pycnogenol intake resulted in significant apoptotic cell death. The first significant apoptotic response was observed after $6 \mathrm{~h}$ of incubation with $20.1 \pm 2.9 \%$ of the cells left apoptotic and $74.2 \pm 1.4 \%$ remaining viable $(\mathrm{p}<0.001)$. Apoptosis reached a maximum after $24 \mathrm{~h}$ of treatment. Here, $28.3 \pm 6.0 \%$ were observed to be apoptotic (vs. $3.4 \pm 1.4 \%$ in control group, $\mathrm{p}<0.001)$ and $65.7 \pm 4.0 \%$ were left viable whereas the percentage of necrotic cells was only $5.5 \pm 3.6 \%$. 

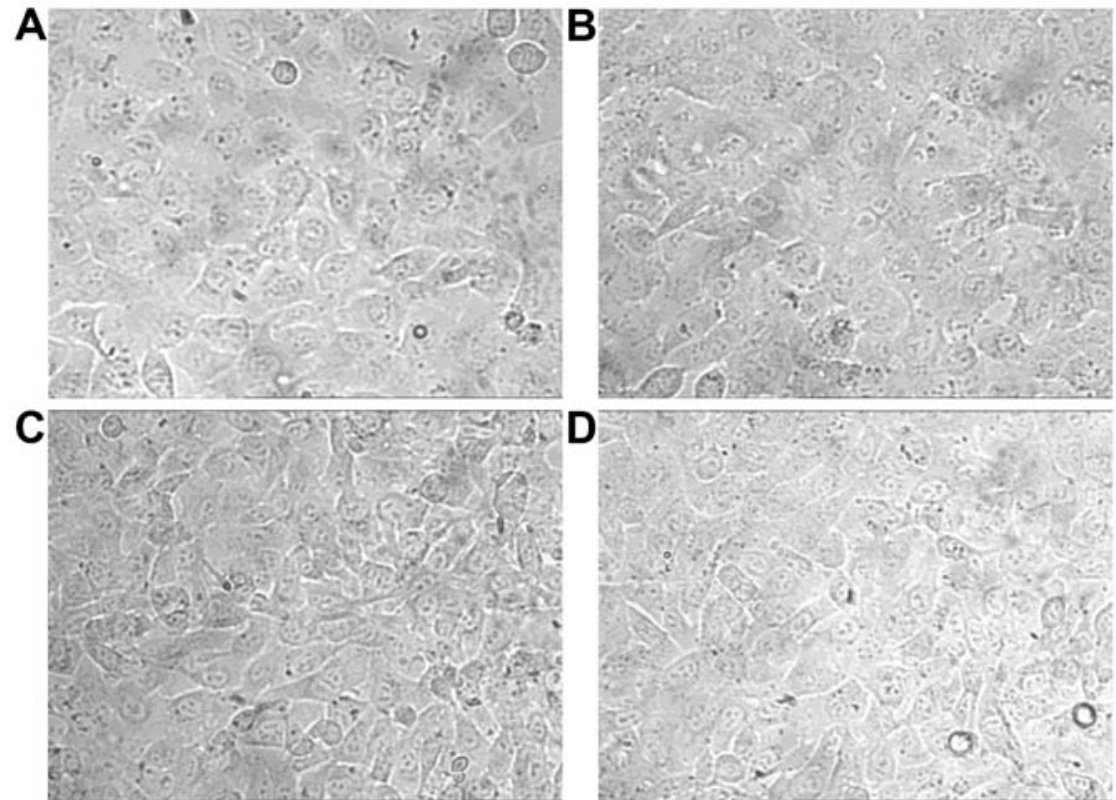

E
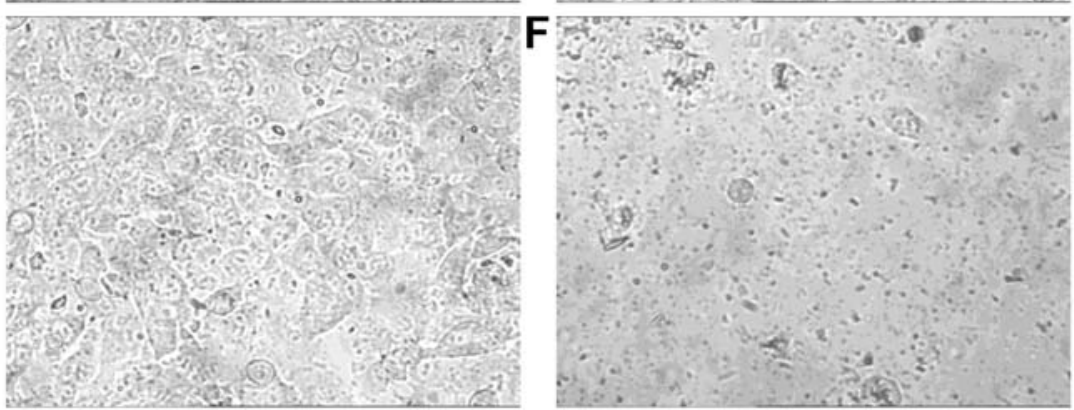

Figure 2. Morphological changes after treatment. Representative photographs (20-fold enlargement) demonstrating morphological changes in HT1080 cells induced by (B) catechin, (C) epicatechin, (D) taxifolin, (E) plasma samples before and (F) after pycnogenol intake following $24 \mathrm{~h}$ of treatment compared with (A) untreated control cells.

Table I. Microarray analysis using GeneTrail software identified significant changes in the following computed KEGG pathway categories with $\mathrm{p}<0.05$ and FDR adjustments (Benjamini-Hochberg).

\begin{tabular}{lccc}
\hline $\begin{array}{l}\text { Selection of significant subcategories } \\
(\alpha=0.05, \text { FDR adjusted })\end{array}$ & p-values & $\begin{array}{c}\text { Expected no. } \\
\text { of regulated genes }\end{array}$ & $\begin{array}{c}\text { Observed no. } \\
\text { of regulated genes }\end{array}$ \\
\hline Apoptosis & 0.002 & 55 & 84 \\
MAPK signalling pathway & 0.028 & 12 & 22 \\
Pathways in cancer & 0.002 & 16 & 33 \\
P53 signalling & 0.002 & 13 & 27 \\
Cell adhesion & 0.002 & 29 & 51 \\
Metabolic pathways & 0.004 & 54 & 32 \\
\hline
\end{tabular}

The analysed genes in the subcategories were significantly up- or downregulated with a $\geq 2$-fold mean change in the treatment group compared to the control. KEGG, Kyoto Encyclopaedia of Genes and Genomes; FDR, false discovery rate.

Only addition of plasma samples after pycnogenol intake induced morphological changes and cell detachment. Catechin, epicatechin, taxifolin and plasma samples before pycnogenol intake did not alter cell morphology and density as observed using bright-field microscopy (Fig. 2). However, plasma samples after pycnogenol intake reduced cell density of HT1080 fibrosarcoma cells indicating decreased rates of cell division and proliferation respectively. Further, it led to shrinkage of cells and dissolution of confluent cell groups followed by complete cell detachment. Longer incubation resulted in obvious morphological aberrations.

Microarray analysis revealed differential gene expression patterns of HT1080 cells treated with plasma samples after pycnogenol intake. Based on comparison analysis algorithm, pycnogenol remarkably altered the expression levels of different combinations of probe sets. In cells treated with plasma samples 
Table II. Summary of the expression changes of apoptosis-related genes for cells treated with human plasma samples after pycnogenol intake compared to untreated cells.

\begin{tabular}{|c|c|c|c|c|}
\hline Gene ID & Gene title & Oncological relevance & $\begin{array}{l}\text { Signal log ratio } \\
\text { (compared to } \\
\text { untreated cells) }\end{array}$ & Refs. \\
\hline FN1 & Fibronectin 1 & $\begin{array}{l}\text { Promotes pulmonary metastasis of human } \\
\text { fibrosarcoma HT } 1080 \text { cells in nude mice. } \\
\text { Upregulation is associated with increased } \\
\text { proliferation, adhesion and invasion of } \\
\text { fibrosarcoma cells in vitro }\end{array}$ & -1.1 & 37,38 \\
\hline CTNNAl & Catenin $\alpha 1$ & $\begin{array}{l}\text { Associated with increased cell survival of } \\
\text { synovial sarcoma cells }\end{array}$ & -1.1 & 39 \\
\hline$L A M C 1$ & Laminin $\gamma 1$ & $\begin{array}{l}\text { Contributes to cancer cell migration and } \\
\text { invasion in prostate cancer }\end{array}$ & -1.0 & 40 \\
\hline RHOA & $\begin{array}{l}\text { Rho GDP dissociation } \\
\text { inhibitor } \alpha\end{array}$ & $\begin{array}{l}\text { Enhances metastatic potential of different } \\
\text { sarcoma cell lines in vivo }\end{array}$ & -0.9 & 47,48 \\
\hline ITGBI & $\begin{array}{l}\text { Integrin, } \beta 1 \text { (fibronectin } \\
\text { receptor, } \beta \text { polypeptide) }\end{array}$ & $\begin{array}{l}\text { Promotes human lung cancer cell invasion } \\
\text { and metastasis in vitro and in vivo. Promotes } \\
\text { proliferation and cell survival of colorectal } \\
\text { carcinoma cells }\end{array}$ & -0.9 & 49,50 \\
\hline$J A K 1$ & Janus kinase 1 & $\begin{array}{l}\text { Inactivation of JAK } 1 \text { in fibrosarcoma cells } \\
\text { leads to loss of invasion in vitro and } \\
\text { metastasis in vivo }\end{array}$ & -0.8 & 46 \\
\hline$P I K 3 C B$ & $\begin{array}{l}\text { Phosphatidylinositol-4,5- } \\
\text { bisphosphate } 3 \text {-kinase, } \\
\text { catalytic subunit } \beta\end{array}$ & $\begin{array}{l}\text { Required for growth of phosphatase and } \\
\text { tensin homolog (PTEN)-deficient } \\
\text { coloncarcinoma cells }\end{array}$ & -0.3 & 51 \\
\hline PIK3RI & $\begin{array}{l}\text { Phosphoinositide-3-kinase, } \\
\text { regulatory subunit } 1(\alpha)\end{array}$ & $\begin{array}{l}\text { Downregulation results in decreased } \\
\text { proliferation, migration, and invasion } \\
\text { in different malignant cell lines }\end{array}$ & -0.3 & 52,53 \\
\hline$A K T 3$ & $\begin{array}{l}\text { V-akt murine thymoma } \\
\text { viral oncogene homolog } 3 \\
\text { (protein kinase } \mathrm{B}, \gamma \text { ) }\end{array}$ & $\begin{array}{l}\text { Contributes to invasive migration and } \\
\text { tumour metastasis in various malignancies }\end{array}$ & -0.3 & 54 \\
\hline$K R A S$ & $\begin{array}{l}\text { V-Ki-ras2 Kirsten rat } \\
\text { sarcoma viral oncogene } \\
\text { homolog }\end{array}$ & $\begin{array}{l}\text { Overexpression promotes progression of } \\
\text { metastatic fibrosarcoma in vivo }\end{array}$ & -0.3 & 55 \\
\hline$D U S P 1$ & $\begin{array}{l}\text { Dual specificity } \\
\text { phosphatase } 1\end{array}$ & $\begin{array}{l}\text { Inhibits proliferation and induces apoptosis } \\
\text { in human hepatocellular and pancreatic } \\
\text { carcinoma }\end{array}$ & 1.0 & 56,57 \\
\hline$B C L A F$ & $\begin{array}{l}\text { BCL2-associated } \\
\text { transcription factor } 1\end{array}$ & $\begin{array}{l}\text { Upregulation is associated with increased } \\
\text { apoptosis and growth inhibition in bladder } \\
\text { cancer cell lines }\end{array}$ & 1.0 & 58 \\
\hline COX3 & Cytochrome $c$ oxidase III & $\begin{array}{l}\text { Decreased expression is associated with } \\
\text { apoptosis resistance in colon cancer cells }\end{array}$ & 0.7 & 59 \\
\hline$M A P K 8$ & $\begin{array}{l}\text { Mitogen-activated protein } \\
\text { kinase } 8\end{array}$ & $\begin{array}{l}\text { Contributes to apoptosis induced by } \\
\text { cytostatics in different sarcoma cell lines }\end{array}$ & 0.5 & 60 \\
\hline
\end{tabular}

after pycnogenol intake, microarray analyses identified noticeable expression changes in 1,128 genes. Of these, $57.5 \%$ (649) were downregulated and $42.5 \%$ (479) upregulated.

To obtain an overview of the biological processes affected by pycnogenol, we analysed the regulated targets of the pathways that were over-represented in our data set using the GeneTrail application (25). Significant over-representation was detected in several pathway categories that included apoptosis, MAPK signalling pathway, pathways in cancer, p53 signalling, cell adhesion and metabolic pathways (Table I). To understand 
the molecular details underlying the diverse modes of cell death in fibrosarcoma cells, we focused on the differentially expressed apoptosis-associated genes that were altered by plasma samples after pycnogenol intake (Fig. 3, Table II).

\section{Discussion}

Fibrosarcomas are rare tumours within the heterogeneous group of soft tissue sarcomas and respond poorly to conventional treatments, such as chemotherapy and radiation. Despite excellent rates of local disease control, treatment options in distant metastatic disease, especially in pulmonary locations, are very limited and have an associated median survival of $<12$ months $(6,7)$. Due to the rarity of fibrosarcomas, the development of new therapeutics has been difficult, and the lack of novel chemotherapy protocols remains a major problem. Additionally, elderly patients with cardiac subdisease are ineligible for doxorubicin-based chemotherapy which is still considered as first-line treatment at metastatic disease stage. For these reasons, there was increasing interest in assessing whether the cardiotoxicity of doxorubicin could be mitigated by antioxidant compounds. In past studies, the maritime pine bark pycnogenol as well as its main constituent catechin were found to protect cardiomyocytes against doxorubicin-induced free radicals attenuating its cardiotoxicity in mice (26-28). Interestingly, pycnogenol and its metabolites are also known to exhibit anticancer activity in a wide range of human cancer cell lines (19-21). Because pycnogenol is extremely well-tolerated and no severe side-effects were ever reported, it is categorized as a nutritional supplement in most of the European countries and readily available. The numerous advantages of pycnogenol inspired us to analyse its anticancer activity in human fibrosarcoma cells.

In our study, plasma samples after pycnogenol intake significantly induced apoptosis in HT1080 cells ex vivo whereas plasma samples before pycnogenol intake did not exhibit any effect. Moreover, it led to decreased cell division and distinct morphological changes. Interestingly, pycnogenol was more effective in apoptosis induction than its main constituents catechin, epicatechin and taxifolin indicating that the metabolised components of pycnogenol interact synergistically.

To further elucidate the actions of metabolised pycnogenol on a molecular basis, we analysed changes in expression of apoptosis-related genes using microarray technology.

Notable gene alterations induced by pycnogenol were found in members of the PI3K/Akt signalling pathway (Table II). Interestingly, the PI3K/Akt pathway is widely dysregulated in many solid malignancies including several soft tissue sarcoma subtypes and many studies have shown this pathway to be vital to the growth and survival of cancer cells (29-32). Here, multiple mechanisms have been found to induce PI3K/Akt signalling, such as activating mutations of key genes such as phosphatidylinositol-4,5-bisphosphate 3-kinase, catalytic subunit $\beta$ (PIK3CB), phosphoinositide-3-kinase, regulatory subunit $1(P I K 3 R I)$ and $\mathrm{V}$-akt murine thymoma viral oncogene homolog 3 (AKT3) (33). In the current study, plasma samples after pycnogenol intake led to a downregulation of PIK3CB, PIK3RI and AKT3 when compared to untreated cells or cells treated with plasma samples before pycnogenol intake suggesting that the PI3K/Akt signalling pathway may play a role

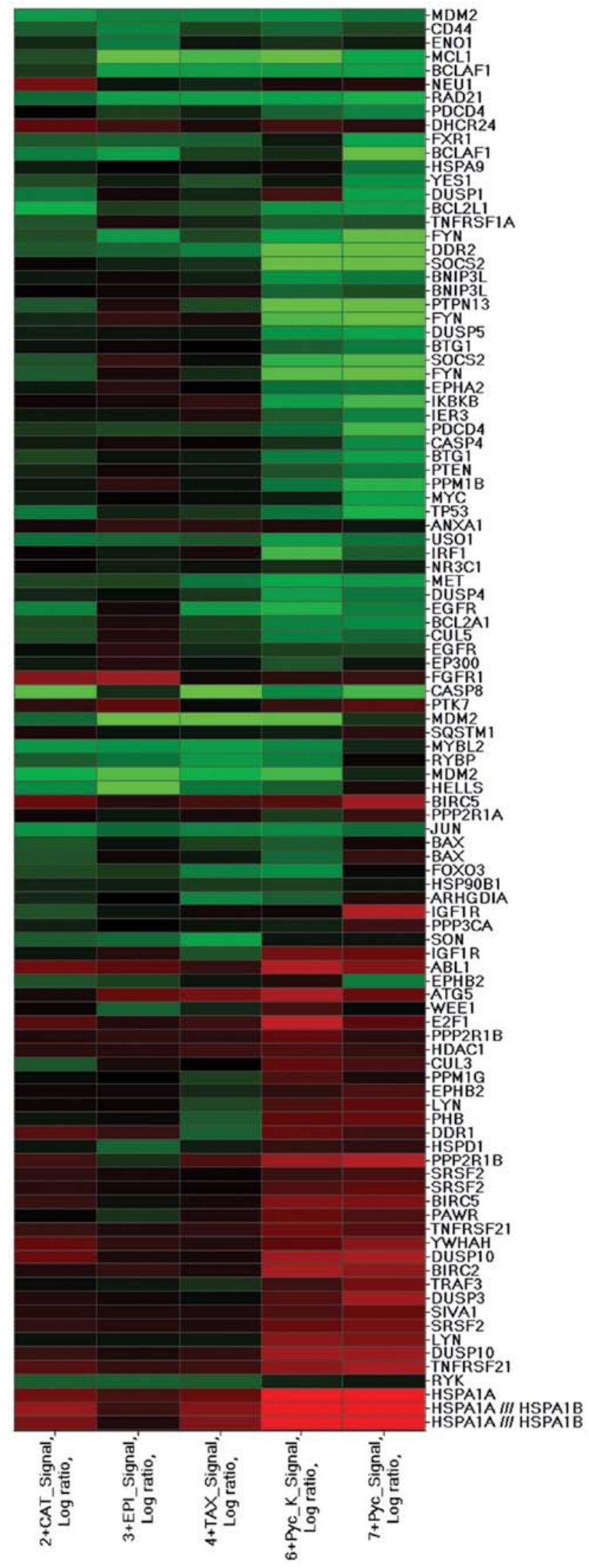

Figure 3. Hierarchical clustering: overall gene expression pattern of reliably measured probe sets. Horizontal rows represent individual probe sets/genes, vertical columns represent individual samples. 2+CAT, catechin; 2+EPI, epicatechin; 4+TAX, taxifolin; 6+Pyc_K, plasma sample before pycnogenol intake; 7+Pyc, plasma sample after pycnogenol intake. Color scale: black, mean (indicates unchanged expression); brightest green, $0.25 \mathrm{x}$ mean (indicates expression level below mean); brightest red, $4 \mathrm{x}$ mean (indicates higher expression level than mean). 
in apoptosis induction in human fibrosarcoma cells (Table II). The only experimental study assessing the impact of PI3K/Akt pathway in fibrosarcoma cells demonstrated that inhibition of PI3K via small molecular inhibitors decreased remarkably the invasive potential of HT1080 cells in vitro (34). However, the role of PI3K/Akt pathway in human fibrosarcoma is still unknown and warrants further research because the novel and well-tolerated group of PI3K inhibitors could be potentially useful therapeutic options.

Interestingly, we found a correlation between apoptotic efficacy of metabolised pycnogenol and downregulation of several genes encoding for cell adhesion proteins such as fibronectin 1 (FN1), catenin $\alpha 1$ (CTNNA1) and laminin $\gamma 1$ (LAMC1) (Table II). Cell adhesion and its underlying pathways play a crucial role in growth, metastasis and development of fibrosarcomas $(35,36)$. In past experimental studies, upregulation of FN1 was shown to increase the invasive potential of HT1080 cells in vitro and to promote their pulmonary metastasis in vivo whereas overexpression of CTNNA1 and LAMC1 were associated with increased cell survival of different malignant cell lines (37-40). However, retrospectively we cannot conclude whether downregulation of these cell adhesion proteins itself led to apoptosis or vice versa. Thus, the appealing hypothesis that disruption of cell adhesion leads to apoptosis in human fibrosarcoma cells requires further experimental support.

Plasma samples with metabolised pycnogenol led also to a downregulation of Janus kinase 1 (JAK1). The JAK/STAT signalling pathway is a key signal transduction pathway implicated in the pathogenesis of many human cancers including several soft tissue sarcoma subtypes $(41,42)$. Constitutive JAK/STAT activity has been demonstrated to cause tumourigenic inflammation and increased proliferation in a wide range of malignant diseases, including malignant fibrous histiocytoma (43-45). In fibrosarcomas, inactivation of JAK1 led to loss of invasion in vitro and metastasis in vivo (46). Recently, pharmacological inhibition of JAK1 was shown to induce apoptosis in rhabdomyosarcoma cells in vivo (42). However, understanding the complex role of JAK1 in sarcoma cell death may provide new opportunities for rational pathway-based therapies and drug development. Several novel JAK/STAT-inhibitors have been tested in clinical trials which could be promising agents in the therapy of metastatic soft tissue sarcomas.

In conclusion, this in vitro study demonstrates that the natural pine bark extract pycnogenol has the potential to induce apoptosis and alter gene expression in fibrosarcoma cells. Although a wide variety of genes and pathways were involved, the PIK3/Akt signalling pathway appears to play a key role in mediating apoptosis of HT1080 cells via pycnogenol metabolites. Pycnogenol is not meant to replace doxorubicin-based chemotherapy in patients with metastatic fibrosarcoma, but it could be a potential mild therapeutic option for patients that are not suitable for chemotherapy and have to undergo palliative treatment. The encouraging results of this study provide experimental support for in vivo trials assessing the effect of pycnogneol in soft tissue sarcomas.

\section{References}

1. Hoos A, Lewis JJ and Brennan MF: Soft tissue sarcoma: prognostic factors and multimodal treatment. Chirurg 71: 787-794, 2000 (In German).
2. Patrikidou A, Domont J, Cioffi A and Le Cesne A: Treating soft tissue sarcomas with adjuvant chemotherapy. Curr Treat Options Oncol 12: 21-31, 2011.

3. Kaushal A and Citrin D: The role of radiation therapy in the management of sarcomas. Surg Clin North Am 88: 629-646, 2008.

4. O'Brien GC, Cahill RA, Bouchier-Hayes DJ and Redmond HP: Co-immunotherapy with interleukin-2 and taurolidine for progressive metastatic melanoma. Ir J Med Sci 175: 10-14, 2006.

5. Solomon LR, Cheesbrough JS, Bhargava R, et al: Observational study of need for thrombolytic therapy and incidence of bacteremia using taurolidine-citrate-heparin, taurolidine-citrate and heparin catheter locks in patients treated with hemodialysis. Semin Dial 25: 233-238, 2012.

6. Karavasilis V, Seddon BM, Ashley S, Al-Muderis O, Fisher C and Judson I: Significant clinical benefit of first-line palliative chemotherapy in advanced soft-tissue sarcoma: retrospective analysis and identification of prognostic factors in 488 patients. Cancer 112: 1585-1591, 2008

7. Billingsley KG, Lewis JJ, Leung DH, Casper ES, Woodruff JM and Brennan MF: Multifactorial analysis of the survival of patients with distant metastasis arising from primary extremity sarcoma. Cancer 85: 389-395, 1999.

8. Pezzi CM, Pollock RE, Evans HL, et al: Preoperative chemotherapy for soft-tissue sarcomas of the extremities. Ann Surg 211: 476-481, 1990

9. Donato Di Paola E, Nielsen OS; EORTC Soft Tissue and Bone Sarcoma Group: The EORTC soft tissue and bone sarcoma group. European Organisation for Research and Treatment of Cancer. Eur J Cancer 38 (Suppl 4): S138-S141, 2002.

10. Nedea EA and DeLaney TF: Sarcoma and skin radiation oncology. Hematol Oncol Clin North Am 20: 401-429, 2006.

11. Brodowicz T, Schwameis E, Widder J, et al: Intensified adjuvant IFADIC chemotherapy for adult soft tissue sarcoma: a prospective randomized feasibility trial. Sarcoma 4: 151-160, 2000.

12. Frustaci S, Gherlinzoni F, De Paoli A, et al: Adjuvant chemotherapy for adult soft tissue sarcomas of the extremities and girdles: results of the Italian randomized cooperative trial. J Clin Oncol 19: 1238-1247, 2001.

13. Judson I, Verweij J, Gelderblom H, et al: Doxorubicin alone versus intensified doxorubicin plus ifosfamide for first-line treatment of advanced or metastatic soft-tissue sarcoma: a randomised controlled phase 3 trial. Lancet Oncol 15: 415-423, 2014.

14. Swain SM, Whaley FS and Ewer MS: Congestive heart failure in patients treated with doxorubicin: a retrospective analysis of three trials. Cancer 97: 2869-2879, 2003.

15. Burningham Z, Hashibe M, Spector L and Schiffman JD: The epidemiology of sarcoma. Clin Sarcoma Res 2: 14, 2012.

16. Grimm T, Skrabala R, Chovanová Z, et al: Single and multiple dose pharmacokinetics of maritime pine bark extract (pycnogenol) after oral administration to healthy volunteers. BMC Clin Pharmacol 6: 4, 2006.

17. Rohdewald P: A review of the French maritime pine bark extract (Pycnogenol), a herbal medication with a diverse clinical pharmacology. Int J Clin Pharmacol Ther 40: 158-168, 2002.

18. Packer L, Rimbach G and Virgili F: Antioxidant activity and biologic properties of a procyanidin-rich extract from pine (Pinus maritima) bark, pycnogenol. Free Radic Biol Med 27: 704-724, 1999.

19. Huang WW, Yang JS, Lin CF, Ho WJ and Lee MR: Pycnogenol induces differentiation and apoptosis in human promyeloid leukemia HL-60 cells. Leuk Res 29: 685-692, 2005.

20. Buz'Zard AR and Lau BH: Pycnogenol reduces talc-induced neoplastic transformation in human ovarian cell cultures. Phytother Res 21: 579-586, 2007.

21. Huynh HT and Teel RW: Selective induction of apoptosis in human mammary cancer cells (MCF-7) by pycnogenol. Anticancer Res 20: 2417-2420, 2000.

22. Belcaro G, Cesarone MR, Genovesi D, et al: Pycnogenol may alleviate adverse effects in oncologic treatment. Panminerva Med 50: 227-234, 2008

23. Chow HH, Hakim IA, Vining DR, et al: Effects of dosing condition on the oral bioavailability of green tea catechins after single-dose administration of Polyphenon $\mathrm{E}$ in healthy individuals. Clin Cancer Res 11: 4627-4633, 2005.

24. Daigeler A, Brenzel C, Bulut D, et al: TRAIL and Taurolidine induce apoptosis and decrease proliferation in human fibrosarcoma. J Exp Clin Cancer Res 27: 82, 2008.

25. Backes C, Keller A, Kuentzer J, et al: GeneTrail - advanced gene set enrichment analysis. Nucleic Acids Res 35: W186-W192, 2007. 
26. Feng WH, Wei HL and Liu GT: Effect of PYCNOGENOL on the toxicity of heart, bone marrow and immune organs as induced by antitumor drugs. Phytomedicine 9: 414-418, 2002.

27. Abd El-Aziz TA, Mohamed RH, Pasha HF and Abdel-Aziz HR Catechin protects against oxidative stress and inflammatorymediated cardiotoxicity in adriamycin-treated rats. Clin Exp Med 12: 233-240, 2012.

28. Du Y and Lou H: Catechin and proanthocyanidin B4 from grape seeds prevent doxorubicin-induced toxicity in cardiomyocytes. Eur J Pharmacol 591: 96-101, 2008.

29. Raynaud FI, Eccles S, Clarke PA, et al: Pharmacologic characterization of a potent inhibitor of class I phosphatidylinositide 3-kinases. Cancer Res 67: 5840-5850, 2007.

30. Willems L, Tamburini J, Chapuis N, Lacombe C, Mayeux P and Bouscary D: PI3K and mTOR signaling pathways in cancer: new data on targeted therapies. Curr Oncol Rep 14: 129-138, 2012.

31. Guo S, Lopez-Marquez H, Fan KC, et al: Synergistic effects of targeted PI3K signaling inhibition and chemotherapy in liposarcoma. PLoS One 9: e93996, 2014.

32. Hernando E, Charytonowicz E, Dudas ME, et al: The AKT-mTOR pathway plays a critical role in the development of leiomyosarcomas. Nat Med 13: 748-753, 2007.

33. Cheung M and Testa JR: Diverse mechanisms of AKT pathway activation in human malignancy. Curr Cancer Drug Targets 13 234-244, 2013

34. Ito S, Koshikawa N, Mochizuki S and Takenaga K: 3-Methyladenine suppresses cell migration and invasion of HT1080 fibrosarcoma cells through inhibiting phosphoinositide 3-kinases independently of autophagy inhibition. Int J Oncol 31: 261-268, 2007.

35. Weinspach D, Seubert B, Schaten S, et al: Role of L1 cell adhesion molecule (L1CAM) in the metastatic cascade: promotion of dissemination, colonization, and metastatic growth. Clin Exp Metastasis 31: 87-100, 2014.

36. Nikitovic D, Berdiaki A, Banos A, Tsatsakis A, Karamanos NK and Tzanakakis GN: Could growth factor-mediated extracellular matrix deposition and degradation offer the ground for directed pharmacological targeting in fibrosarcoma? Curr Med Chem 20 2868-2880, 2013.

37. Gong M, Ueda Y, Kanazawa Y, Tsuchiya H and Ma YG: Association of gene FN1 with pulmonary metastasis of human fibrosarcoma. Zhonghua Zhong Liu Za Zhi 29: 14-16, 2007 (In Chinese).

38. Ying L, Lau A, Alvira CM, et al: LC3-mediated fibronectin mRNA translation induces fibrosarcoma growth by increasing connective tissue growth factor. J Cell Sci 122: 1441-1451, 2009

39. Sato H, Hasegawa T, Kanai Y, et al: Expression of cadherins and their undercoat proteins (alpha-, beta-, and gamma-catenins and p120) and accumulation of beta-catenin with no gene mutations in synovial sarcoma. Virchows Arch 438: 23-30, 2001.

40. Nishikawa R, Goto Y, Kojima S, et al: Tumor-suppressive microRNA-29s inhibit cancer cell migration and invasion via targeting LAMC1 in prostate cancer. Int J Oncol 45: 401-410, 2014

41. Shouda T, Hiraoka K, Komiya S, et al: Suppression of IL-6 production and proliferation by blocking STAT3 activation in malignant soft tissue tumor cells. Cancer Lett 231: 176-184, 2006.

42. Yan S, Li Z and Thiele CJ: Inhibition of STAT3 with orally active JAK inhibitor, AZD1480, decreases tumor growth in Neuroblastoma and Pediatric Sarcomas in vitro and in vivo. Oncotarget 4: 433-445, 2013

43. Li N, Grivennikov SI and Karin M: The unholy trinity: inflammation, cytokines, and STAT3 shape the cancer microenvironment. Cancer Cell 19: 429-431, 2011.
44. Redell MS, Ruiz MJ, Alonzo TA, Gerbing RB and Tweardy DJ: Stat 3 signaling in acute myeloid leukemia: ligand-dependent and -independent activation and induction of apoptosis by a novel small-molecule Stat3 inhibitor. Blood 117: 5701-5709, 2011.

45. Senft C, Priester M, Polacin M, et al: Inhibition of the JAK-2/STAT3 signaling pathway impedes the migratory and invasive potential of human glioblastoma cells. J Neurooncol 101: 393-403, 2011.

46. Teng Y, Xie X, Walker S, White DT, Mumm JS and Cowell JK: Evaluating human cancer cell metastasis in zebrafish. BMC Cancer 13: 453, 2013.

47. Miyamoto C, Maehata Y, Ozawa S, et al: Fasudil suppresses fibrosarcoma growth by stimulating secretion of the chemokine CXCL14/BRAK. J Pharmacol Sci 120: 241-249, 2012.

48. Kosla J, Paňková D, Plachý J, et al: Metastasis of aggressive amoeboid sarcoma cells is dependent on Rho/ROCK/MLC signaling. Cell Commun Signal 11: 51, 2013.

49. Wang XM, Li J, Yan MX, et al: Integrative analyses identify osteopontin, LAMB3 and ITGB1 as critical pro-metastatic genes for lung cancer. PLoS One 8: e55714, 2013.

50. Song J, Zhang J, Wang J, et al: $\beta 1$ integrin modulates tumor growth and apoptosis of human colorectal cancer. Oncol Rep 32: 302-308, 2014

51. Wee S, Wiederschain D, Maira SM, et al: PTEN-deficient cancers depend on PIK3CB. Proc Natl Acad Sci USA 105: 13057-13062, 2008.

52. Weber GL, Parat MO, Binder ZA, Gallia GL and Riggins GJ: Abrogation of PIK3CA or PIK3R1 reduces proliferation, migration, and invasion in glioblastoma multiforme cells. Oncotarget 2: 833-849, 2011.

53. Fu Y, Zhang Q, Kang C, et al: Inhibitory effects of adenovirus mediated COX-2, Akt1 and PIK3R1 shRNA on the growth of malignant tumor cells in vitro and in vivo. Int J Oncol 35: 583-591, 2009.

54. Chin YR and Toker A: Function of Akt/PKB signaling to cell motility, invasion and the tumor stroma in cancer. Cell Signal 21: 470-476, 2009.

55. Algarra I, Perez M, Serrano MJ, Garrido F and Gaforio JJ: c-K-ras overexpression is characteristic for metastases derived from a methylcholanthrene-induced fibrosarcoma. Invasion Metastasis 18: 261-270, 1998-1999.

56. Calvisi DF, Pinna F, Meloni F, et al: Dual-specificity phosphatase 1 ubiquitination in extracellular signal-regulated kinase-mediated control of growth in human hepatocellular carcinoma. Cancer Res 68: 4192-4200, 2008

57. Gil-Araujo B, Toledo Lobo MV, Gutiérrez-Salmerón M, et al: Dual specificity phosphatase 1 expression inversely correlates with NF- $\mathrm{KB}$ activity and expression in prostate cancer and promotes apoptosis through a p38 MAPK dependent mechanism. Mol Oncol 8: 27-38, 2014

58. Yoshitomi T, Kawakami K, Enokida H, et al: Restoration of miR-517a expression induces cell apoptosis in bladder cancer cell lines. Oncol Rep 25: 1661-1668, 2011.

59. Payne CM, Holubec H, Bernstein C, et al: Crypt-restricted loss and decreased protein expression of cytochrome $\mathrm{C}$ oxidase subunit I as potential hypothesis-driven biomarkers of colon cancer risk. Cancer Epidemiol Biomarkers Prev 14: 2066-2075, 2005.

60. Koyama T, Mikami T, Koyama T, et al: Apoptosis induced by chemotherapeutic agents involves c-Jun $\mathrm{N}$-terminal kinase activation in sarcoma cell lines. J Orthop Res 24: 1153-1162, 2006. 